\title{
SOCIOCRITICISMO: INSTITUCIONALIDAD E HISTORIA DE UN CUERPO TEÓRICO EN FORMACIÓN
}

\author{
María Amoretti Hurtado \\ Al maestro, con cariño
}

\begin{abstract}
RESUMEN
En este artículo se presenta un resumen y una revisión de los avatares institucionales y las controversias epistemológicas en el proceso de formación de la sociocrítica como una oferta académica determinada históricamente.
\end{abstract}

\begin{abstract}
This article offers a brief outline of the institutional vicissitudes and the epistemological controversies in the process of building the socio-critics as an historically defined academic option.
\end{abstract}

\section{Justificación}

Entender una disciplina no se limita únicamente a la comprensión de su minimum epistemológico o a la captación del modo de racionalidad que le es intrínseco, aspecto en el cual ya hemos venido insistiendo en algunos otros artículos en que hemos hecho aplicación explícita de varias herramientas sociocríticas.

Toda disciplina es algo más que un cuerpo teórico. Toda disciplina es a la vez una práctica inserta en el tiempo y determinada también desde su exterior. Por eso, como cualquier otra, la Sociocrítica es una empresa no sólo colectiva sino que además histórica. En este artículo, se expondrán las condiciones que posibilitaron su emergencia y determinaron la definición de sus metas y medios, como también su devenir.

A pesar de su juventud, la Sociocrítica ha tenido una clara evolución gracias al trabajo constante de sus investigadores, quienes, por medio de una asociación internacional, se han organizado de modo que cada dos años se sientan a dialogar, a intercambiar opiniones, a hacer recuento de sus avances, pero, sobre todo, a comunicar los resultados del falsamiento popperiano de sus hipótesis y corregir y afinar más sus herramientas de trabajo.

De esta forma, podríamos afirmar que, al menos en el caso de la sociocrítica de Montpellier, se perciben tres momentos o etapas diferentes. Por lo tanto, su devenir presenta tres cortes significativos con dominancias interdisciplinarias diferentes. 
Sin embargo, vamos a comenzar por el comienzo, es decir, por una caracterización general de esta empresa académica y las circunstancias en que se origina.

\section{Avatares coyunturales de su origen y crisis epistémica inevitable}

La Sociocrítica es una disciplina que nace de una cierta coyuntura intelectual francesa a finales de la década de los setenta y principios de la siguiente; pero, muy a diferencia de tantas otras orientaciones de origen francés dedicadas al estudio de la literatura, la Sociocrítica tiene una especial marca de origen: su preferencia por, el estudio de las literaturas española e hispanoamericana.

La Sociocrítica se relaciona estrecha pero problematizadamente con ese enorme campo conocido hoy como Sociología de la Literatura.

Según Paul Cornea (1976), la tendencia social en el análisis literario se ha convertido en una moda y por ello también sufre los riesgos de toda popularidad; es decir, que, si bien tiene la ventaja de despertar vocaciones, también tiene el inconveniente de aumentar las confusiones, los malos entendidos y las simplificaciones abusivas.

La Sociología de la Literatura parece haberse fragmentado al infinito y parece también haberse convertido en una demagogia de procedimientos, lenguajes y perspectivas conceptuales. Dentro de ese paisaje, la Sociocrítica ha sufrido una evolución que refleja la problemática propia de un campo caracterizado por los rasgos que Paul Cornea describe.

En los primeros encuentros sociocríticos, realizados en Europa y Norteamérica (Canadá, propiamente), se prestó una especial atención a aplicaciones muy concretas; por ejemplo, en la reunión de 1973, el texto novelesco fue el foco de atención. En el encuentro de 1979, la discusión se centró en el tema de las mediaciones. Ya en 1980, se pasó a cuestiones de metodología. Poco a poco, las discusiones se fueron encaminando hacia una problemática de la teorización, para finalmente desembocar en un diálogo explícitamente polémico que generó en la reunión de 1989 algunas incomodidades. En este encuentro, definitivamente, los esfuerzos se enrumbaron hacia la búsqueda del objeto sociocrítico, lo cual creó bastante perplejidad ya que, después una década de irrupción en el mercado académico, se suponía que esta disciplina había definido y asumido desde sus inicios su correspondiente objeto de estudio.

Pierrette Malcuzynski (1991: 14) se hacía, al respecto, las siguientes interrogantes: "¿Qué había pasado con el objeto sociocrítico? ¿Se había "extraviado" de cierto modo en el camino? ¿Había perdido contenido o pertinencia? ¿Se había diseminado?"

Esta situación ponía sobremanera en evidencia que el mayor problema de la Sociocrítica ha sido siempre su deslinde dentro del gigantesco campo de la Sociología de la Literatura y, debido quizá a la fluctuación de las aproximaciones reunidas bajo la etiqueta de Sociocrítica, a menudo se confunde abusivamente la Sociología de la Literatura con la Sociocrítica. Por eso, a principios de los años setenta, se acuñó el término "Socio-crítica" (entonces con guión), insistiendo en la diferencia que existía entre esta disciplina y la Sociología de la Literatura.

No obstante, con el transcurso del tiempo, tal vez oída pero no entendida, esa distinción se fue convirtiendo en un problema de objeto. Todavía en el encuentro de 1980, se notaba una confusión terminológica y conceptual en las dos disciplinas que fue claramente confrontada en la reunión de 1989. 
A pesar de la diversidad de las contribuciones sociocríticas, que hace decir a Duchet que sería más propio hablar de las sociocríticas y no de la Sociocrítica (1979), es absolutamente imprescindible no confundir -como advierte Malcuzynski (1991)- diversidad con indeterminación del objeto.

\section{Determinando el objeto de la Sociocrítica}

La Sociocrítica, entonces, desde el principio, se fija como meta el proponer una teoría fundada en la definición previa de un objeto de estudio específico diferente del que se había dado hasta la fecha la Sociología de la Literatura; esto implicaba, entonces, la creación de una nueva disciplina y, para evitar confusiones, el establecimiento de una nueva terminología.

El mismo nacimiento del término Sociocrítica es uno y diverso también. Nació simultáneamente en dos sitios diferentes, lo cual provocó por mucho tiempo una discusión acerca del creador del neologismo con que se bautizó esta propuesta teórica de la literatura y su método correspondiente.

La confusión no fue francamente dilucidada sino en 1995, en el Congreso que se llevó a cabo en Marruecos. Allí se aclararon los pormenores de su emergencia. Fue así como se supo que el término "sociocrítica" había aparecido por primera vez en Montpellier, en el curso de uno de los primeros coloquios que un joven equipo de investigadores, dirigidos por Edmond Cros, organizaba cada año en el convento de las dominicas de Saint Mathieu de Tréviers, en la víspera del movimiento universitario del 68.

Con guión o sin él (Sociocrítica), el término situaba las preocupaciones de este equipo en estrecha relación con la Psycho-critique -también con guión entonces- de Charles Mauron. Así nació, en 1975, el CERS (Centre d'Études et Recherches Sociocritiques) en Montpellier. Este grupo pretendía proponer una especie de radiografía de la escritura que permitiera hacer visibles los valores sociales que en lo profundo del texto de ficción lo organizaban.

En la misma época, en París, Claude Duchet y un cierto número de investigadores agrupados en torno a la revista Littérature acuñaban de la misma forma el término. Sin que hubiera conexión alguna entre un grupo y el otro, ambos manifestaban, no obstante, preocupaciones semejantes y se centraban en el estudio de los procesos de textualización con el objetivo de discernir en ellos los valores sociales específicos que los orientaban.

Así, no se trataba de definir la naturaleza social del fenómeno literario, sino más bien del estatuto de lo social dentro del texto literario.

Para ello, era necesario, entonces, precisar los instrumentos requeridos para el análisis del sentido dentro del texto y, analizando este sentido, resaltar la problemática de la circulación de los discursos sociales como dinámica constitutiva de la práctica literaria.

Como se observará, el campo sociocrítico postula una doble práctica que, tradicionalmente, se había concebido como dos aproximaciones autónomas a la literatura, independientes la una de la otra y hasta cierto punto entendidas como contradictorias e incompatibles: el Formalismo y la Sociología de la Literatura. De modo que, en Sociocrítica, la especificidad estética de lo literario será enfocada en relación con los contenidos y las prácticas socioculturales de la época en cuestión, sin cuya comprensión la misma dimensión del valor del texto no sería comprensible. 
Al texto así asumido, se le denominó en adelante "sociotexto" (Duchet 1979), el cual es entendido como producción en sí, pero, al mismo tiempo, como producto de una práctica socio-ideológica.

De lo anterior se deriva que una perspectiva sociocrítica entiende las estructuras de mediación que intervienen entre las estructuras de sociedad y las estructuras textuales como de naturaleza discursiva, de modo que el examen se orienta hacia las redes discursivas que efectúan el trabajo de textualización y sus metamorfoseantes estructuraciones en una sociedad determinada. Por eso, la Sociocrítica hace una notoria diferencia entre intertextualidad e interdiscursividad, y le da un énfasis mayor a esta última. Se trata, fundamentalmente, de buscar un factor de convergencia (el texto semiótico crosiano) en el que se intercepten lo semiótico y lo ideológico (el ideosema crosiano).

A continuación, transcribo las palabras de Malcuzynski (1991: 25), quien resume así el análisis sociocrítico:

\footnotetext{
Trabajar las condiciones de existencia de la práctica textual, de la especificidad estética del texto irreductible a su material lingüístico, de su socialidad, subrayando la necesidad de poner en relieve los varios discursos necesariamente comprometidos en un texto dado, así como distinguir entre diferentes tipos de discursos. Más específicamente se trata de afirmar la preeminencia de lo interdiscursivo con respecto al discurso (...) Metodológicamente hablando, la Sociocrítica consiste en trabajar, remitiendo a procesos de interdiscursividad, elementos de la textualidad.
}

Para concluir este apartado, deberíamos insistir entonces en el hecho de que, de una manera general, la Sociocrítica se distingue de la Sociología de la Literatura tradicional, primero, por su objeto; es decir, que en el dominio de la Literatura, a la Sociocrítica le interesa la literariedad exclusivamente y su estudio se limita a ello, pero entendiendo que la literariedad no es otra cosa que una poética de la socialidad. Además, contrariamente a la Sociología de la Literatura, lo que dentro de este dominio le interesa es el interior del texto, es decir, su foco está -como lo dice Duchet (1979: 4) - en "la organización interna de los textos, sus sistemas de funcionamiento, sus redes de sentido, sus tensiones, el encuentro en ellos de saberes y discursos heterogéneos".

La sociocrítica se distingue también, y sobre todo, por el hecho de que ella postula que la realidad referencial sufre, bajo el efecto de la escritura, un proceso de transformación semántica que codifica ese referente bajo la forma de elementos estructurales y formales, lo que supone que el análisis debe reconstituir el conjunto de mediaciones que han deconstruido, desplazado, reorganizado y resemantizado las diferentes representaciones de lo vivido individual y colectivo en el texto.

Las diferentes corrientes de la Sociocrítica intervienen o convergen también, aunque en diversos grados, en los diferentes debates relativos a las grandes mediaciones institucionales y lingüísticas. Su atención se ha centrado, sin embargo, más particularmente, en los espacios polifónicos y conflictivos discernibles en la materia pretextual y textual como en las modalidades en que lo social se inscribe en el texto; lo que Cros (1980) ha llamado "zonas de impacto". Es a este paso de lo pretextual a lo textual a lo que más énfasis le ha dado el trabajo investigativo de Cros, como lo veremos más adelante. 


\section{La diversidad sociocrítica. Las sociocríticas}

Así, heredera también del estructuralismo genético (especialmente en sus nociones de sujeto transindividual y de no-consciente), esta disciplina surge entonces de la coincidencia de investigaciones individuales y colectivas llevadas a cabo independientemente unas de las otras. Por eso, como lo señalaban Duchet y Malcuzynski, ella no constituye un conjunto verdaderamente homogéneo sino diverso.

Este hecho se presenta de modo evidente si se analizan los espacios ideológicos o epistemológicos en los que ciertos centros de investigación o ciertos autores se apoyan. Por ejemplo, mientras que Edmond Cros, Claude Duchet y Jurgen Link se afilian al materialismo histórico y tienden a privilegiar las mediaciones colectivas y la relación con la Historia, Pierre Zima está más cerca de la teoría crítica de la Escuela de Franckfort, tal y como ha sido desarrollada por Adorno, Horkheimer y Marcuse. La importancia de la pragmática es, por otra parte, muy relevante en las aplicaciones de Antonio Gómez Moriana, quien hace un énfasis detallado en los componentes de las modalidades enunciativas de los textos y en el orden del discurso entendido a la manera foucaldiana.

Así ha nacido un cierto número de campos de investigación y de conceptos operatorios entre los cuales se destacan unos y se encabalgan otros. Citamos a modo de ejemplo los siguientes:

1. Sociograma (Claude Duchet)

2. Evento discursivo (Jürgen Link)

3. Sociolecto (Pierre Zima)

4. Ideosema y campo morfogenético (Edmond Cros)

5. Discurso social (Marc Angenot y Régine Robin)

6. Tercer interpretante (Monique Carcaud-Macaire)

\section{La especificidad de la escuela montpelleriana de sociocrítica}

Sin embargo, la mayoría de los centros de investigación se refieren principalmente a las posiciones de Edmond Cros. Una razón para ello es el liderato que, por intermedio de Cros, ha asumido la Universidad de Montpellier en el marco internacional de esta disciplina y sus contactos en Hispanoamérica. Así, algunos de los jóvenes docentes que van a preparar su doctorado en Montpellier crean, a su regreso al país de origen, centros o grupos de investigacíon que continúan ligados al CERS de Montpellier por medio de su red de publicaciones y de la afiliación al IIS, Instituto Internacional de Sociocrítica. En el caso de Costa Rica, fue una profesora becaria de la Universidad de Costa Rica (UCR. San José) la que inició en este campo el contacto entre esta universidad y la Universidad de Montpellier en 1980 y quien, a su regreso, creó la primera cátedra de Sociocrítica y organizó un grupo de estudios sociocríticos que tiene plena vigencia en la actualidad, hasta el punto de que el interés por esta opción metodológica se ha extendido, a partir de 1997, a sus sedes regionales (Sede de Occidente, en San Ramón de Alajuela). 
Fue por intermedio de este primer contacto y en ocasión de la primera visita de E. Cros a Costa Rica que la Universidad Nacional Autónoma de Costa Rica (UNA, Heredia) entró en relación con la Sociocrítica, en la persona de Sonia Marta Mora. Existen, entonces, dos grupos de estudios sociocríticos en Costa Rica y un tercero en formación en San Ramón de Alajuela.

Otra razón de la preferencia de muchos de los investigadores sociocríticos por las propuestas de Cros es el hecho de que ellas constituyen quizá el conjunto más ordenado, didáctica y metodológicamente hablando, como también el más constante y el más bibliográficamente accesible, pues sus publicaciones tienen ahora, en la mayoría de los casos, ediciones no sólo en francés, sino también en español e inglés. Las traducciones de sus libros, sobre todo del francés al español, se han venido produciendo con mayor celeridad en los últimos años.

Cros desarrolla, a partir de los setenta, un conjunto de proposiciones que darán lugar a una serie de manifiestos teóricos y aplicaciones concretas regularmente publicadas. Entre sus contribuciones más significativas están los siguientes libros:

1975. L'aristocrate et le camaval des gueux. Montpellier. CERS.

1976. Propositions pour une Sociocritique. Montpellier. CERS.

1980. Ideología y genética textual. El caso del Buscón. Madrid. Planeta.

1983. Théorie et pratique sociocritiques. Montpellier. CERS.

Esta última obra, coeditada por el CERS y Éditions Sociales, fue traducida al español y publicada por Gredos en 1986. También fue editada en inglés por la prestigiosa colección de Prensas de la Universidad de Minnesota en 1988.

Otras publicaciones más de Cros son:

1991. De l'engendrement des formes. Montpellier. CERS.

1995. D'un sujet a l'autre. Sociocritique et Psychanalyse. Montpellier. CERS.

Estas publicaciones, además de dar una amplia difusión a algo que poco a poco fue apareciendo como una disciplina en los medios universitarios de Hispanoamérica y América del Norte, señalan y resumen las preocupaciones y los logros de campos de investigaciones específicas.

En efecto, E. Cros se ha dedicado en el curso de los últimos años a estudiar los procesos que operan en el pasaje de lo prediscursivo a lo discursivo y de lo pretextual a lo textual, lo que lo ha conducido a proponer el concepto de "ideosema". Según él, la cadena de representaciones que se manifiestan como conjuntos estructurados en el texto y que le dan a este su dinamismo no puede ser tratada de una manera estrechamente semántica. Lo que él entiende por estructuración es la relación de signo a signo y su convergencia semiótica; por eso propone un enfoque semiótico. Por otra parte, en el origen de esas estructuraciones siempre encontramos una práctica social y de ahí que el ideosema sea concebido por Cros como un articulador a la vez semiótico y discursivo. Semiótico porque estructura los sistemas de signos icónicos, gestuales o lingüísticos socializados; y discursivo porque, transpuesto dentro del texto, asegura una función estructurante de la misma naturaleza. 
El ideosema administra la programación textual concebida como un campo morfogenético que acepta únicamente aquellas formas que tengan la misma resonancia magnética del campo.

Es el hecho de que estas propuestas teóricas se traducen en términos de una semiótica, lo que permite su eventual utilización en otros dominios que no sean los literarios.

Así, la Sociocrítica Montpelleriana rechaza el que se la limite a una "sociología del texto literario" y pretende ser apta para dar cuenta de la "socialidad" de todo producto cultural, es decir, de la configuración social en él implicada; de ahí la expansión de su campo de aplicación y de ahí que se dé como tarea la redefinición del objeto de la investigación en sociología cultural, tarea que va a ser la meta esencial del futuro Instituto Intemacional de Sociocrítica.

\section{Nacimiento del IIS}

Con ocasión de uno de los primeros encuentros internacionales, se le da carácter jurídico y existencia legal al Instituto Internacional de Sociocrítica (IIS) en noviembre de 1991, aunque desde hacía ya varios años su existencia era un hecho. A pesar de que no tenía constitución jurídica, ya había venido funcionando este grupo de investigadores, gracias al asocio que les proporcionaba una preocupación teórica común.

Al IIS se le concibe de alguna manera como una prolongación del CERS (Centre d'Études et de Recherches Sociocritiques) que había sido creado, como ya lo vimos, en 1975, en Montpellier.

El Instituto se da como objetivo el estudio de las marcas y el análisis del funcionamiento ideológico de la producción cultural en general (cine, pintura, música, etc.) y literaria en particular; como también el análisis de las articulaciones que ligan estas producciones con las estructuras de sociedad. Por lo tanto, entre sus mayores preocupaciones está la definición de "objeto cultural", "sujeto cultural", "texto cultural" en los diferentes productos de la cultura (literarios, fílmicos, picturales, musicales, etc.) y la propuesta de herramientas y modos de aproximación específicas a estos objetos.

\section{El hispanismo en el corazón de la sociocrítica y su difusión}

Como lo ha destacado Malcuzynski (1991), el campo privilegiado, pero no exclusivo, de la investigación sociocrítica ha sido la narrativa realista y la mayoría de los títulos de las publicaciones se concentran en las culturas hispánicas, pues muchos de los que se llaman sociocríticos son de antemano hispanistas o, al menos, si sus trabajos se enmarcan fuera del campo propiamente hispánico, se trata de investigadores que, en uno u otro momento, han tenido algún vínculo con América Latina.

Es de destacar también en esta preferencia por las literaturas hispánicas, sobre todo, la labor que lleva a cabo Edmond Cros, quien ha estado a cargo de la dirección del Centro de Estudios e Investigaciones Sociocríticas (CERS) en la Universidad de Montpellier, Francia. 
Las publicaciones de este Centro se organizan en dos Revistas (Imprévue y Co-textes) y una serie titulada "Colección de Estudios Sociocríticos". Allí se agrupan monografías de literatura y cultura hispánica que van desde la picaresca hasta la narrativa contemporánea tanto española como latinoamericana. Allí también se difunden trabajos de académicos y artistas de diferentes latitudes de América Latina y otras regiones como África y Norteamérica. Tal es el caso del volumen de Imprévue dedicado a la poesía de Laureano Albán (Imprévue. 84-1).

En Canadá, existe otro foco de publicaciones: la Editorial Le Préambule, dirigida por Antonio Gómez Moriana de la Universidad de Montréal, quien es un especialista en los Siglos de Oro de la literatura hispánica. En esta editorial, dentro de una colección llamada "El Universo del discurso", se han publicado estudios sobre el relato de viajes como un género que está en el fundamento mismo de la literatura hispanoamericana y monografías relativas a obras particulares de la literatura hispanoamericana, incluida una, traducida al francés, en torno a la novela de Roberto Brenes Mesén, Lázaro de Betania, expresión en prosa del modernismo tardío en Costa Rica, de Daniéle Trottier (1987). Este libro luego fue publicado por la Editorial de la Universidad de Costa Rica en su versión española en el año 1993.

El incontestable y marcado interés por las culturas y literaturas hispánicas por parte de la mayoría de los sociocríticos del IIS ha hecho que, durante la década de los años ochenta, la Sociocrítica haya comenzado a difundirse de manera más o menos institucionalizada como disciplina, dentro del marco universitario y académico de investigación cultural y literaria en varios centros latinoamericanos y en otros lugares del mundo.

En Norteamérica, por ejemplo, se han traducido varias de las obras esenciales de Cros, tal es el caso -que ya mencionamos- del compendio teórico titulado Teoría y Prácticas sociocríticas, el cual ha sido publicado en su versión inglesa por la Universidad de Minnesota. También en Norteamérica, la Universidad de Pittsburg, en copatrocinio con la Universidad Paul Valéry, Montpellier III, ha publicado la revista Sociocriticism por varios años, dentro de la cual ahora figuran dos académicas costarricenses en su Comité de Lectura.

Aunque fue la Universidad de Guadalajara, México, la primera en América Latina en hacer contacto con esta disciplina, gracias a la existencia de un convenio de larga tradición entre esa casa de enseñanza y la Universidad de Montpellier, la primera cátedra de Sociocrítica fundada en Hispanoamérica es la de la Universidad de Costa Rica. Desde 1982, la Escuela de Filología, Linguiística y Literatura de esa Universidad ofrece no sólo seminarios de Sociocrítica, sino que estos cursos han permanecido desde entonces entre las opciones teórico-metodológicas que los estudiantes avanzados del plan de estudios en Filología Española o del posgrado en Literaturas Hispánicas pueden elegir como herramientas básicas en sus investigaciones literarias. No obstante, estos cursos han sido constantemente utilizados también por estudiantes de Historia, Psicología, Periodismo, Artes Plásticas y Antropología.

Dada ya la experiencia de casi dos décadas, los investigadores de la Universidad de Costa Rica han producido material didáctico y bibliográfico generado en la práctica docente e investigativa de esa disciplina y, como se pudo observar en el V Congreso, este material se está utilizando en los centros sociocríticos de Colombia (Medellín), México (Guadalajara) y Argentina (Salta y Rosario).

Se cuentan ya seis libros editados por los sociocríticos costarricenses (y tres más en ciernes); entre ellos se incluye un diccionario de términos sociocríticos editado en 1994 bajo el sello también de la Editorial de la Universidad de Costa Rica. 
Todas las investigaciones sociocríticas producidas por los académicos costarricenses han sido financiadas y publicadas por la Universidad de Costa Rica; excepción hecha de dos: el caso de la investigación de Sonia Marta Mora dedicada a El Periquillo Sarniento y publicada bajo el copatrocinio del IIS y de la Universidad Nacional de Costa Rica en Heredia (1995). Esta última universidad costarricense (UNA) sacó, además, a la luz un estudio sociocrítico dedicado a El Matadero (Ramírez 1997).

La última novedad la ha tirado de nuevo la Editorial de la Universidad de Costa Rica. Se trata de un libro titulado Fray Gerundio de Campazas o la corrupción del lenguaje (Chen 1999), el cual ha sido promocionado de la siguiente manera en el Semanario de la Universidad de Costa Rica, hebdomadario que, dicho sea de paso, es de "cobertura" nacional:

La Editorial de nuestra Universidad acaba de publicar un ensayo que versa sobre un libro español del siglo XVIII. Prácticamente yo diría que con este libro de Jorge Chen Sham, se abre una línea editorial nueva. Muy pocas veces tenemos la oportunidad de leer ediciones costarricenses que se ocupen de la literatura española y mucho menos de la del siglo XVIII. Pero un libro tan viejo puede traer a colación problemas muy actuales y creo que este es el caso del libro del que se ocupa Chen: Fray Gerundio de Campazas, inolvidable paradigma de los malos predicadores.

(...)

De ahí que en los nuevos contextos, el texto mantiene su espíritu beligerante e, independientemente del debate entre la intención autorial y la intención del lector, hay una intención textual que se sigue generando y con la cual se enfrenta también esta lectura moderna, que es la de Chen.

En el texto, lo que está dicho escrito está y el efecto, aunque matizable, es irreversible. Después de todo hay allí un sentido que se genera en buena ley retórica y el texto sigue debatiéndose en un alegato que también nosotros comprendemos porque el problema de la palabra y su uso sigue teniendo vigencia.

Con sotana o sin sotana, la "historia del famoso predicador" todavía existe y la retórica se viste de modos distintos pero sigue usando sus mismos mecanismos. Por eso la historia de fray Gerundio nos recuerda a la de los falsos letrados de hoy y sus retóricas. Púlpito, sermón y predicador podrían ser conmutados por comunicación, medio e ideología mediática, el predicador de nuestro tiempo. La retórica no ha quedado hoy ni siquiera en el discurso político (que ya no convence a nadie), por eso aquella y éste se han refugiado hoy en la publicidad y desde ahí despliegan sus efectos persuasivos.

(...)

Del siglo XVIII a éste que ya termina, la retórica sigue siendo un saber clave en la creación de ficciones y sigue todavía fascinando por sus poderes persuasivos; quizá sea esta evidencia el aporte más interesante del análisis de Chen, gracias al cual un texto del siglo XVIII nos lee mejor que muchas obras contemporáneas (Amoretti 1999)

Editado en Holanda y escrito desde el Centro Sociocrítico de la Universidad de Varsovia por Pierrette Malkuzynski, circula desde 1991 un volumen colectivo en español titulado Sociocríticas. Prácticas textuales. Cultura de fronteras, cuyo propósito específico es el de "proporcionar algunos textos fundamentales que familiaricen al hispanohablante con el aparato crítico y analítico de la Sociocrítica así como con el conjunto terminológico, nocional y conceptual específico que esta disciplina posee" (Malcuzynski 1991: 3). En este volumen ya se citan algunas de las contribuciones bibliográficas de Costa Rica. 


\section{Los encuentros internacionales}

\subsection{Primer Congreso Internacional de Sociocrítica (1989)}

Entre los esfuerzos colectivos importantes ya hemos mencionado el Primer Congreso Internacional de Sociocrítica celebrado en Montpellier en julio de 1989, con la participación de teóricos y críticos literarios de varias universidades de Alemania, Austria, Bélgica, Canadá, Colombia, Costa Rica, Francia, Inglaterra, Italia, México, Puerto Rico y Polonia.

\subsection{Segundo Congreso Internacional (1991)}

El Segundo Congreso tuvo lugar en Guadalajara, México, en noviembre de 1991.

En general, en este encuentro, al igual que en los de 1973 y 1979, volvió a privar la atención en aplicaciones concretas, entre las cuales resultó inolvidable la realizada por Sol Villasèque a propósito del texto plástico de Dalí "El sueño de Colón".

Se dejó de lado la discusión epistemológica, excepción hecha de dos ponencias: la de Tatiana Bubnova, quien definía la literatura como "una suspensión del orden del discurso", del orden foucaldiano del discurso, y la de Monique Carcaud-Macaire, quien ya comenzaba a vislumbrar su idea del "tercer interpretante" a partir de la adaptación del texto literario al texto fílmico (véase su publicación posterior Pour une lecture sociocritique de l'adaptation cinématographique. 1995). Aparte de estas ponencias, se echó de menos, entonces, el calor de la polémica del anterior congreso en Montpellier

Haciendo un esfuerzo por evaluar la capacidad persuasiva de esta disciplina frente a sus competidores en el "nicho ecológico" del campo de la teoría y la crítica literaria, una participante costarricense deploraba el Congreso de esta manera:

\footnotetext{
Recurro a Lakatos. Según este filósofo de la ciencia, todo programa de investigación científica (todo paradigma, diría Khum) está constituido fundamentalmente por creencias metafísicas y por una faja o cinturón protector compuesto por una serie de hipótesis auxiliares, las cuales normalmente se contrastan y evolucionan. Por el contrario, el contenido del núcleo es más resistente al cambio.

Así, creo que cuando en este congreso se ha logrado discutir algo, a lo más que se ha llegado -y bastante tímidamente, por lo demás- es a la reflexión sobre esa faja de hipótesis y esta faja es la que impide normalmente el acceso al núcleo metafísico. Este núcleo metafísico respondería al valor del nudo epistémico de la Sociocrítica y a la forma en que este responde a las demandas de la comunidad científica como un todo. ¿Qué es “conocer” en Sociocrítica? ¿Qué clase de racionalidad se da ella misma y por qué? ¿Para qué sirve? Creo que es el momento de comenzar a discutirlo. Propongo que para el próximo congreso se fijen objetivos precisos en este sentido, de modo que las participaciones sean reflexiones teóricas o aplicaciones que signifiquen un verdadero estímulo para el diálogo y la discusión del saber sociocrítico. Como por ejemplo, es necesario determinar las formas de impacto de nuestro propio discurso teórico; el modo en que se relacionan, dentro de nuestra propia semiótica científica, la genealogía de Foucault, la dialogía bajtiniana y la genética de Cros.

Es urgente revisar esas zonas de impacto a partir de su propio ideosema, que sería precisamente el punto de origen de la estructuración de nuestro propio discurso teórico, su núcleo epistémico y metafísico (De la ponencia presentada por Amoretti el día de la clausura).
}

Tal vez se podría afirmar que entre las novedades de este encuentro estuvo el tema de las reflexiones en torno al impacto de la Sociocrítica en el campo de la enseñanza y la didáctica universitaria, problemática también planteada por Amoretti. 
A este respecto, tenemos, entre otras, las siguientes conclusiones:

1. La Sociocrítica busca un tipo de saber integrado: un saber específico pero derivado de una relación recíproca con otros saberes.

2. Otorga a la literaturología un estatuto nuevo, abriéndole un lugar especial en el conjunto de las Ciencias Sociales.

3. Abre campos nuevos de trabajo, pues el análisis del texto, sobre la base de la semiótica y de la pragmática, se vuelve aplicable a otros productos culturales como la pintura, la música y el cine.

4. Desde el punto de vista didáctico, plantea retos que promueven no sólo la reflexión pedagógica y la epistemológica, sino también que incentiva la creatividad tanto en los docentes como en los estudiantes.

La trascendencia de este encuentro estuvo también en el hecho de que, en esa ocasión, se le dio existencia legal al Instituto Internacional de Sociocrítica, el cual, actualmente, reagrupa centros de estudios e investigaciones sociocríticas de las siguientes universidades (ver además cuadros adjuntos):

Facultad de Letras, Universidad de Abidjan (Costa de Marfil)

Universidad Nacional e Instituto Caro y Cuervo (Bogotá, Colombia)

Universidad de Fes (Marruecos)

Facultad de Filosofía y Letras (Universidad de Guadalajara, México)

Universidad de Costa Rica (San José, Costa Rica)

Universidad Nacional de Costa Rica (Heredia, Costa Rica)

Universidad Paul Valéry (Francia)

Universidad de Perpignan (Francia)

Universidad de Manheim, Estudios Románicos (Alemania)

Universidad de Varsovia (Polonia)

\subsection{Tercer Congreso Internacional (1993)}

Se llevó a cabo en Costa Rica, del 21 al 26 de noviembre de 1994, con el copatrocinio de la Universidad de Costa Rica y la Universidad Nacional. Este encuentro estuvo nuevamente dominado por la presentación de aplicaciones concretas. Por ello, entre las conclusiones fundamentales estuvo el señalamiento de la ampliación del campo de las aplicaciones sociocríticas.

En esta reunión, se destacó la diversidad de los objetos culturales abordados; aparte de las aplicaciones en plástica y música que ya habían llamado la atención en el Congreso de Guadalajara, en el de Costa Rica se expusieron trabajos en archivística, cartografía, publicidad y manifestaciones diversas de la cultura popular como el chiste y algunos programas radiofónicos de gran audiencia en Hispanoamérica, especialmente en los años cincuenta; tal fue el caso del famoso "Trespatines y la Tremenda Corte". 


\subsection{Cuarto Congreso Internacional (1995)}

La Universidad de Sibi Mohamed Ben Abdellah fue la sede, en la ciudad de Fes, Marruecos y se desarrolló del 26 al 29 de noviembre de 1995.

Si en sus primeras etapas, a finales de los setenta, el interés de la Sociocrítica se concentró en las nociones de ideología e institución, para precisar con mayor claridad la función de la literatura en tanto práctica social, actualmente sus esfuerzos se orientan más bien hacia la problemática del sujeto cultural y los procesos identitarios. Este interés se hizo evidente en algunas de las ponencias plenarias de ese congreso en las que también se bordeó la relación Historia y Literatura, Historia y Sociocrítica.

A este respecto, la última propuesta de investigación hecha por Edmond Cros, ahora Director del Instituto Internacional de Sociocrítica (IIS) se dirige a la consideración del impacto que sobre los procesos identitarios representa la organización de los nuevos conjuntos socioeconómicos, originados por la creación de bloques de mercado. Para Cros:

\footnotetext{
La rectificación de los contornos de los conjuntos socioeconómicos que conducen a la organización de vastos sectores de mercado (ALENA, MERCOSUR), sobre el modelo de la CEE, plantea a más o menos largo plazo, el problema de la rectificación de las identidades políticas y culturales (Propuesta para Alfa, CEE, 1994).
}

Por lo tanto, el objetivo de la actual propuesta de investigación es analizar las posibles consecuencias que las integraciones económicas macrorregionales puedan tener sobre el imaginario identitario.

La idea es la de efectuar estudios descriptivos abordados en función de las relaciones históricas que se han establecido entre culturas dominantes y culturas dominadas. Se trata, entonces, de considerar los productos culturales que han traducido y siguen traduciendo situaciones históricas caracterizadas por la imposición de un imaginario, de una lengua o de una escritura sobre otras. Es decir, se trata del análisis de los fenómenos de colonización del imaginario.

Se propone, pues, desarrollar la investigación sobre las bases teóricas elaboradas por la antropología, determinadas por las tesis "autoctonistas", que sostienen que toda evolución es local, y las "difusionistas", que privilegian el impacto de las culturas exteriores sobre la evolución de las sociedades. Entre los temas de interés están:

1. La evolución de las lenguas bajo ese tipo de dominación o después de que esta haya finalizado (diferentes idiomas latinoamericanos, lenguas precolombinas, vasco, catalán, etc.), privilegiando las zonas de contacto y de conflictos como índices de las tensiones sociales.

2. Las colonizaciones del imaginario cuyos efectos son perceptibles en la creación cultural.

3. Las especificidades de las revoluciones respectivas de las literaturas concernidas en los contextos de las instituciones literarias y culturales implicadas.

Los resultados de estas investigaciones se propondrán a las diferentes comunidades implicadas para una eventual aplicación en el campo de la Educación, en el que -como se sabe- se reproduce y transmite por excelencia el discurso identitario (Tomado de la propuesta para Alfa. Edmond Cros 1994). 
Es dentro de esa orientación que las nociones de Cros sobre "sujeto cultural" y "texto cultural" se enmarcan.

Así, el Cuarto Congreso Internacional de Sociocrítica llamó la atención, por primera vez, sobre consideraciones éticas que hoy son motivo de una nueva confrontación y cuestionamiento de los marcos epistemológicos vigentes, tal y como lo ha planteado posteriormente una de las investigadoras participantes, Vittoria Borso, en un artículo titulado "Literatura y discurso o la mirada desde afuera. Impulsos de una "hispanoamericanística" internacional para la reorganización del saber en las ciencias humanas" (En Klengel 1996).

Para que se tenga una mejor idea de algunos de los márgenes que la actual reflexión de la disciplina y su última propuesta investigativa provoca en estos momentos, nos permitiremos transcribir el inquietante párrafo conclusivo de ese magnífico trabajo de Vittoria Borso (Universidad de Dusseldorf, Alemania):

\footnotetext{
Con esta operación epistemológica, la relación entre lo otro y lo mismo se invierte. Lo otro, los otros, los Hispanoamericanos no son ya ni los subalternos, ni el ornamento de un sujeto occidental canibalista que con la alteridad ensancha su identidad. Somos más bien nosotros, los europeos, quienes nos descubrimos mirados por los otros, por los que, desde afuera, irritan la seguridad de nuestra patria epistemológica. Desde esta óptica, otra cara de la historia se abre a los ojos. La historia de la colonización de América -una colonización primero territorial, luego del saber-, ya no se ve como la historia del poder y de la impotencia de los subalternos, tampoco de su rebelión contra los maestros, sino más bien como la historia de la impotencia de un pensamiento occidental, presente en ambos lados del océano, un pensamiento centrado en sí mismo, en el cuidado de sí mismo, en su propio deseo narcisista de identidad, un pensamiento sujetado a la obsesión de encontrar su identidad. Es en contra de esta tendencia que necesitamos una perspecitva intercultural, interhistórica e "intersticial" en las Humanidades (1996. Pág. del manuscrito original: 22).
}

Como se puede desprender de este párrafo, las inquietudes van más allá del nivel epistemológico; las actuales preocupaciones de la Sociocrítica se están situando estrictamente en el plano de la ética a partir de la monumentalización del discurso y de la observación del mismo discurso teórico como un evento discursivo que, al igual que todo discurso, moldea bajo la presión de su enunciación y de su asunción un sujeto que le es propio: un sujeto autocrítico que pueda mirar en sí mismo las identidades prestadas que lo constituyen y sus propias contradicciones. A este tema va a volver Duchet en el siguiente congreso, como ya se verá.

Para clausurar esa cuarta reunión, se entregó la obra más voluminosa de la historia de la disciplina: un gigantesco compendio de trabajos sociocríticos (más de 1500 páginas) agrupados en dos tomos (Carcaud-Macaire 1997). Se trata de una publicación del IIS en homenaje a Edmond Cros, en el que estudiantes, colegas y amigos, investigadores de diferentes comunidades académicas, le rinden tributo al maestro y al fundador de una empresa académica que, a través de la Sociocrítica, se ha puesto al servicio de las letras y las culturas hispánicas. De parte de Costa Rica, colaboraron en esa obra Jorge Chen, Estébana Matarrita, Ivonne Robles y quien escribe estas páginas.

Ha sido gracias al empeño y los esfuerzos de Edmond Cros que la Sociocrítica es hoy una razón de encuentro, intercambio, amistad y conocimiento mutuo entre hispanistas de tres continentes: África, América y Europa. 


\subsection{Quinto Congreso Internacional (1997)}

Se desarrolló en Francia, de nuevo. Para conmemorar las dos décadas de existencia de esta disciplina, se regresó ritualmente a su primera sede: el convento de las dominicas de Saint Mathieu de Tréviers.

El ambiente conventual de recogimiento y lo aislado de la sede de las grandes concentraciones de población propiciaron una mayor interacción intelectual. A ello también habría que agregar la presencia de dos sociocríticos, cuya labor se ha centrado en la producción de conocimiento teórico: Duchet y Zima, quienes formaron junto con Cros un trío académico muy interesante.

Esto, más las novedades en la organización que frecuentemente se le da a este tipo de reuniones académicas, hizo del quinto congreso un encuentro mucho más fructífero y provechoso que algunos de los anteriores.

Así, podríamos afirmar que la atención de este congreso se centró sobre todo en lograr una forma de organización que permitiera un espacio más amplio de discusión y una participación al ciento por ciento.

Para lograrlo, las exposiciones de los trabajos se limitaron en extremo (con máximo estricto de 15 minutos). Esta medida permitió dos cosas:

a. Que todas las exposiciones se hicieran en reunión plenaria, de modo que nadie se privara de escuchar ninguna de las comunicaciones.

b. Que al final del día se diera un espacio amplio de discusión sobre nociones o problemas de antemano solicitados por los congresistas o emergidos de algunas de las exposiciones.

Todo lo anterior fue posible porque, por una parte, se exigieron resúmenes de dos cuartillas sobre cada ponencia, los cuales fueron distribuidos y conocidos por los participantes con anterioridad a su presentación oral; y, por otra, se había solicitado con antelación el orden de las preocupaciones teóricas o metodológicas de los congresistas.

Así se logró detectar con antelación, como lo había sugerido Amoretti en Guadalajara, en qué campos, criterios o nociones estaban las preocupaciones o los problemas que la mayoría de los miembros del IIS se planteaba. El siguiente gráfico muestra, por ejemplo, las preferencias de los miembros del IIS en esa ocasión:

Cuadro 1

Nociones teóricas

1. Sujeto cultural

$30 \%$

2. Texto cultural

$22 \%$

3. Morfogénesis

$21 \%$

4. Ideologema

$20 \%$

5. Cronotopo

$6 \%$

6. Ideosema

$6 \%$

7. Sociolecto

$6 \%$

8. Ideología-interdiscursividad-interculturalidad y metaculturalidad-

$3 \%$ la noción de destinatario 


\begin{tabular}{|lr|}
\hline Sujeto cultural & 30 \\
Texto cultural & 22 \\
Morfogénesis & 21 \\
Ideologema & 20 \\
Cronotopo & 6 \\
Ideosema & 6 \\
Sociolecto & 6 \\
Otros & 3 \\
\hline
\end{tabular}

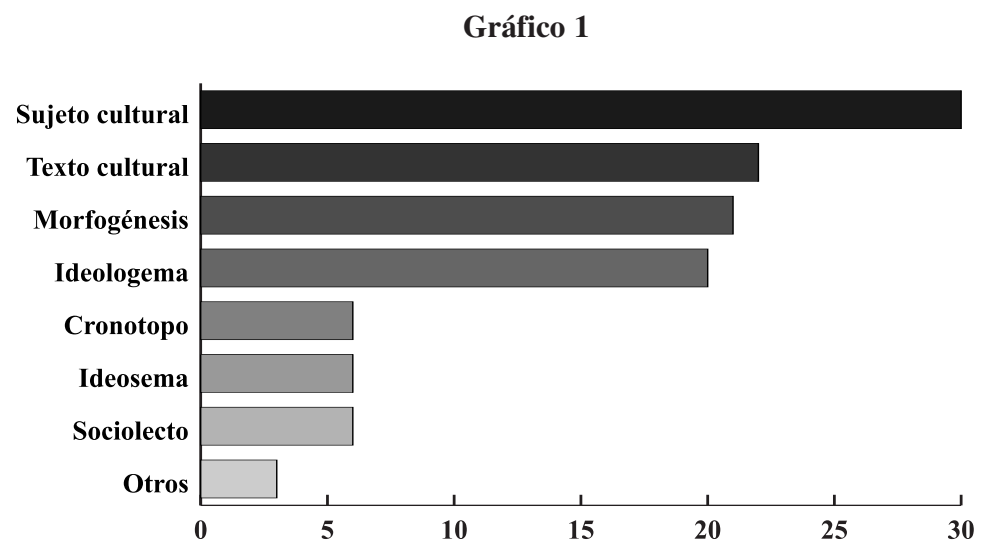

Como se puede observar en el gráfico, las dos nociones más solicitadas para una discusión resultaron ser las más recientes y las más vinculadas con la investigación sobre las identidades.

Otra de las novedades organizativas fue el hecho de que las sesiones se ordenaran por centro afiliado, con el propósito de evidenciar la identidad de los grupos de investigación y los esfuerzos que se hacen por un trabajo concertado en equipo.

En la discusión que se llevó a cabo efectivamente, se establecieron algunas relaciones y deslindes, como los siguientes:

1. La doxa y lo dóxico, relación de cooperación o de conflicto entre el imaginario consensual y la imaginación creadora (Duchet).

2. Relación doxa-texto cultural (Duchet).

3. Relación texto cultural-cronotopo: las formas que juegan un rol de base en la interpretación. (Esta discusión fue provocada por la ponencia de Monique de Lope, de la Universidad de Provenza, acerca del funcionamiento de "la casa de campo" como cronotopo en la novela española de los años sesenta).

4. Deslindes necesarios como el que se dio entre sujeto cultural-sujeto nacional (Amoretti).

5. Ideologema-Ideosema (Duchet). 
Al trabajar en la diferenciación entre la doxa (del lado del estereotipo) y lo dóxico (del lado de la transgresión), Duchet volvía a insistir en el nivel ético (relación con los valores, con la ideología consensual) del texto literario y su crítica destacando, sin embargo, una vez más, el carácter paradojal de la literatura y la asunción que de él hace abiertamente la Sociocrítica.

El equipo de Costa Rica puso en el tapete nuevamente la confrontación entre historia y literatura, sobre todo en el nivel de los insumos relativos a cada uno de esos campos, a la naturaleza de sus discursos y a sus metodologías. Se hizo referencia concreta a la investigación histórica y a la investigación literaria dentro del área académica específica de su país.

Naturalmente que el asunto de la didáctica volvió a surgir. En esta ocasión, en la voz de Isabel Tournier, quien se refirió al comentario de texto y su enseñanza. Aunque, según se anunciaba en el programa, la conferencia de clausura a cargo de Sonia Marta Mora, entonces Vicerrectora Académica de la Universidad Nacional de Costa Rica (Heredia), abordaría el tema "Funcionalidad didáctica de los métodos sociocríticos: una experiencia en Costa Rica", al final fue sustituido por otro que lo abordó tangencialmente a través de la creación de los llamados Colegios Académicos en Costa Rica.

Con el grupo de Costa Rica, este congreso inauguró también una actividad inédita hasta la fecha en estos encuentros sociocríticos internacionales, pues se organizó una mesa redonda acerca de un autor costarricense (Rafael A. Herra), quien además participó en el Congreso como observador. Con este tipo de actividades, los centros afiliados tienen también ahora una nueva forma de dar a conocer y promover la literatura de sus países de origen.

Para terminar, debe señalarse la contribución de Michèle Soriano en este Congreso, quien abordó de manera excepcional la cuestión de la teoría de género en una ponencia en que hacía un acercamiento sociocrítico acerca de los soportes y apuestas genéricas.

Todos estos encuentros, aparte de promover la disciplina sociocrítica, constituyen un excelente medio de difusión y homenaje a las letras y la cultura hispánicas que por esta vía se fortalecen, gracias al apoyo mutuo entre sus investigadores en el dominio científico y a la organización de un sistema para la difusión de sus publicaciones.

A fin de cuentas, la Sociocrítica, tanto en su dimensión epistemológica como en su dimensión institucional, lleva a cabo una empresa transdisciplinaria e intercultural orientada especialmente hacia la comunidad hispánica como unidad cultural en la creación artística y en el trabajo académico.

\section{Balance histórico}

Decíamos, al inicio de este artículo, que es posible vislumbrar tres etapas diferentes en la sociocrítica Montpelleriana. Después de haber recorrido el itinerario académico de la disciplina, estamos en mejores condiciones de captar las diferencias entre esos períodos o cortes significativos, caracterizados por dominancias interdisciplinarias diferentes. 


\subsection{Primera etapa}

El primer período, fuertemente atraído todavía por el estructuralismo genético de Goldmann, hace uso de conceptos como "genotexto" y "fenotexto" que, aunque incrustados en una genética textual particular, provocaban reminiscencias kristevianas desde todo punto de vista inconvenientes por su incompatibilidad con el núcleo duro de la semiótica científica del método sociocrítico. Por esa razón, a menudo se debía estar insistiendo en la necesidad de no confundir estas nociones con las definiciones y el uso que de ellas hacía la entonces influyente figura de Julia Kristeva.

En esta etapa, para describir el funcionamiento textual, se utilizan metáforas epistemológicas provenientes de las matemáticas, de la computación y la biología. Para el primer caso, baste citar las ordenadas y las abcisas estructuralistas (paradigma y sintagma, respectivamente) que Cros instrumentaliza para explicar la generación del sentido textual, cuyo centro ubica precisamente en el vértice (genotexto); para el caso de la segunda, el genotexto es calificado como "centro programador" y para el tercer caso, baste con mencionar la noción de "genética textual" que va a originar el título del segundo libro de Cros: Ideología y genética textual. El caso del Buscón (1980). A este primer período también pertenece otra obra suya titulada Thèorie et pratique sociocritiques (1983).

\subsection{Segunda etapa}

En la segunda etapa, el énfasis predominante será biológico. Cros se apoya ahora en los estudios sobre embriología de Rupert Sheldrake y la idea de los campos de resonancia magnética, para proponer algo así como una morfética, pero siempre dentro de una concepción genética.

La noción clave aquí es la de ideosema. Esta noción significa, a nuestro juicio, un avance interesante en la precisión de los instrumentos de la caja de herramientas sociocrítica y significa también una superación del antiguo concepto y prestado neologismo del "genotexto".

El ideosema es un instrumento de análisis mucho más preciso que el de genotexto, pues al destacarse como un articulador entre lo semiótico (prácticas sociales) y lo discursivo (prácticas textualizantes) realiza de modo más eficiente la meta clave de la sociocrítica, poniendo en evidencia directa la relación entre texto y sociedad en el diseño mismo del modelo de producción textual; mientras que el "genotexto" sólo destacaba la dinámica de esa producción y la describía, para cada caso, en términos conceptuales que, si bien provenían de una articulación, no la mostraba de manera tan explícita como sí lo hace el ideosema, en su papel morfogenético y las formas virtuales en él implicadas.

A esta segunda etapa corresponde el libro de Cros, titulado De l'engendrement des formes (1991). 


\subsection{Tercera etapa}

La última y tercera etapa se hace sentir en las preocupaciones manifestadas en los dos últimos congresos (el cuarto, en Marruecos y el quinto, en Montpellier) y que ya hemos comentado. Ahora el interés está en la problemática del sujeto y en la cuestión identitaria. De ahí que la propuesta montpelleriana se aproxima ahora todavía más al psicoanálisis lacaniano.

Aquí creemos que es decisiva la colaboración de Annie Bussière Perrin con E. Cros. El título del libro de este último es más que elocuente: D'un sujet a l'autre. Sociocritique et Psychanalyse (1995).

Para enmarcar la problemática identitaria, Cros reelabora la noción de "sujeto cultural" haciendo un esfuerzo por diferenciarlo del "sujeto del deseo" en el relieve del texto y afina, además, el concepto bajtiniano de "texto cultural" como una verdadera herramienta de trabajo para objetivar a aquel. Así, esta noción adquiere, a nuestro juicio y experiencia, mayor operatividad. Pero, mientras que Bajtín propone el texto cultural como constitutivo del horizonte ideológico del texto, Cros describe, a partir de allí, el detalle de su composición y explica todavía más su funcionamiento.

Entendido como la instancia más próxima al sujeto cultural, esta noción de Cros caracteriza al "texto cultural", según los tres rasgos siguientes:

1. Su carácter fragmentario (es un segmento de intertexto de un cierto tipo).

2. Su alto contenido dóxico (pues se mueve sólo en intertextos de ese tipo, o sea, de alta condensación dóxica).

3. Su carácter de esquema, particularmente de esquema narrativo (con lo cual se entronca con una epistemología de la narratividad, al estilo de Hayden White, quien relaciona lo dóxico y lo narrativo al considerar que donde quiera que haya narración hay una presunción moral).

Para que se vea claramente la influencia de Lacan, transcribimos la siguiente paráfrasis que esta autora ha hecho de la relación que ese libro establece entre ciertas ideas psicoanalíticas y la Sociocrítica:

\footnotetext{
El texto cultural no tiene vida autónoma, sólo existe reproducido en un objeto cultural bajo la forma de una organización semiótica subyacente que se da a ver sólo fragmentariamente por medio de huellas imperceptibles y fugaces que requieren de un análisis de alguna forma sintomal o entimemático. Por eso Cros, parafraseando a Lacan dice que así como el inconsciente está estructurado y funciona como un lenguaje, la literatura está estructurada y funciona como el sueño, es decir, a base de elusiones, ilusiones y alusiones, equívocos, rodeos que se lanzan tras las metáforas. Por eso, al interpretar la literatura somos al mismo tiempo interpretados por ella puesto que lo inconsciente es lo que ha sido leído pero igualmente es lector (Tomado del documento "La realidad social. ¿Cómo interpretarla?". Material de la cátedra de Sociocrítica de la Universidad de Costa Rica).
}

En Costa Rica, se han tratado de visualizar todas estas relaciones entre los diferentes focos de influencia que la Sociocrítica incorpora en su discurso científico. Para comprender mejor las estructuraciones de su red de certidumbres y determinar poco a poco la diferencia entre los elementos que podrían estar en el cinturón periférico de las hipótesis secundarias y 
el contenido eidético-metafísico del núcleo, los estudiantes de Sociocrítica, en el seminario de 1998 en la Sede de Occidente de la Universidad de Costa Rica, hicieron un esfuerzo por montar un diagrama que mostrara las relaciones de fuerza entre los diferentes cuerpos teóricos que la disciplina incorpora.

De las propuestas de esta tercera etapa que hemos venido describiendo, surgen otros problemas, más necesidades deslindantes como, por ejemplo, la relación entre el sociograma de Duchet, el texto cultural como lo enuncia Cros y el cronotopo bajtiniano. Algo de esta discusión tuvo inicio en el último congreso en Montpellier (1997). Esperamos que se retome en el sexto.

Por lo pronto, adelantamos algo de nuestra propia cosecha: el sociograma de Duchet es homólogo al ideologema tal y como lo entienden Bajtín y sus seguidores: permanencia que forma una cierta memoria de la doxa en medio de una masa de hechos sociodiscursivos poco limitados, poco aislables, muy borrosos, pero sobre todo omnipresentes, aunque conflictivos. Esta es la materia analizable (denominada, por lo demás, de diversos modos: "discurso social", "rumor social", por ejemplo) para lograr discernir la configuración social específica de la época de la que el texto emerge. Estos conceptos de "sociograma", "discurso social", "rumor social” han sido elaborados por el grupo de París (Duchet) y el de Canadá (Angenot-Robin).

Mientras que el cronotopo focaliza el acontecimiento en la categoría espacio temporal para captar el devenir de la sociedad y los marcos de las diversas narrativas que orientan la intelección de una época, el texto cultural de Cros busca en los fragmentos de un esquema narrativo heredado, relativamente estable (por las variaciones de un cinturón periférico de elementos secundarios que lo protege), ciertos vectores de sentido que desembocan en una valencia ética (el núcleo duro de la doxa) normalmente traducible en términos de una máxima y la sentencia que ella implica.

El cronotopo se centra en la composición y el acabado y, aunque nos da acceso a los "ojos" con que la colectividad mira su realidad y a la forma en que la interpreta y representa, hace más énfasis en los moldes cognoscitivos. Mientras tanto, el texto cultural hace énfasis más bien en la fenomenología de una ética convertida en texto: pues la doxa que se pone en juego, al tiempo que nos juega, revela la jugada. Es decir, que a través del texto cultural nos enfrentamos a la parusía del momento ideológico y sus estructuras simbólicas; el texto cultural hace posible el advenimiento del universo moral que nos enfrenta a nuestros propios valores; él provoca el momento de revelación de nuestros actos auténticos y de nuestros actos falsarios.

Para lograr esa especie de "diagrama" de la socialidad específica de la época, se puede recurrir tanto al "texto cultural" como al "cronotopo"; la diferencia de cada una de estas nociones-herramienta es que ponen énfasis distintos y ellas se sitúan espacialmente en ejes diferentes de la metáfora matemáticia inicial de Cros. A continuación, vamos a explicarnos con mayor amplitud.

Por supuesto que es posible llegar a ese universo moral también a través del análisis de los cronotopos y sus empotramientos (como lo demuestra Bajín en su ya clásico análisis de Rabelais), pero el camino podría resultar más largo y penoso.

Los dos conceptos no se contraponen, tan sólo presentan énfasis diferentes y recorridos distintos. Su relación es más bien de complementaridad, pero si hubiera que jerarquizarlos, el texto cultural quedaría habitando dentro del cronotopo; el texto cultural es un componente 
del cronotopo en tanto que, en el mismo empotramiento de estos, el texto cultural representa la huella, el rastro que van dejando los cronotopos deconstruidos por la presión de aquel que "imaginiza" la configuración social de su época.

Siendo el cronotopo el índice de la forma histórica de la textualización, se coloca más cómodamente en el eje intertextual; pero un cronotopo se diferencia de los demás gracias a los textos culturales que lo guían desde su propio interior.

Al ser el texto cultural un signo del orden dóxico, se ubica más bien en el eje de la interdiscursividad; de ahí que complazca mejor las aspiraciones críticas del análisis social de los textos y sus formas.

Estando el cronotopo en el eje de la intertextualidad que redistribuye tradiciones estéticas previas, se homologa a la cuestión genérica, sólo que, afectado por el eje interdiscursivo de la lectura del tiempo sobre el tiempo, el cronotopo nos ayuda a remodelar el concepto de género tomando en consideración la poiesis social que lo sustenta. El cronotopo puede, así, ser retraducido como una especie de modelización secundaria de naturaleza estética.

No obstante, ambos, cronotopo y texto cultural, actúan como consabido y promueven los horizontes de lectura y sus espectativas, ya que en los dos se juega un modelo de la realidad que es común a la comunidad y las formas interpretativas por ella heredadas. Ambos son, pues, una categoría del contenido y de la forma en la literatura.

Ya ha sido convocado el sexto congreso (Granada, España. Noviembre de 1999). Chicharro Chamorro, de la Universidad de Granada, está embarcado en la difícil tarea de su preparación. Veremos, pues, muy próximamente, qué balance nos ofrece la discusión en este encuentro.

Se preven nuevos deslindes, esta vez con Bajtín, el pensamiento de mayor capacidad persuasiva en este momento dentro de la comunidad científica a la que pertenecemos: la teoría y crítica literarias. El mejor y más complejo conocimiento de este autor, provocado en los últimos años por la publicación de algunos de sus textos inéditos, las traducciones al español cada vez más frecuentes e inmediatas y los magníficos trabajos interpretativos sobre sus teorías (como los de Bubnova, Zavala, Holquist, Morson y Emerson) nos ponen en situación de medir más adecuadamente su influencia en los marcos de la sociocrítica montpelleriana.

El equipo de Holanda, liderado intelectualmente por Iris Zavala, propone enfoques sociocríticos que son muy dignos de considerar por su agudeza y sus entronques explícitos con la escuela de París (Duchet) e implícitos con el grupo de Cros (véase la parte introductoria de su libro Bajtín y la posmodernidad de 1991). Dentro de este equipo, es importante el esfuerzo de Miriam Díaz-Diocaretz por forjar una contribución a la teoría de género desde las ideas de Bajtín (véanse los cuatro tomos de La breve historia feminista de la literatura española en lengua castellana).

El trabajo de Tatiana Bubnova tampoco es algo que se deba pasar por alto, sobre todo después de su participación en el Congreso de Guadalajara y sus últimas publicaciones acerca de Bajtín (1996), en las que toma en cuenta los resultados sociocríticos del grupo de Montpellier, particularmente los de Cros en torno a la cultura de la risa popular.

Una aproximación crítica a estas relaciones entre Bajtín y la Sociocrítica (véase Zavala 1991) podrían revelarnos los límites de esa aceptada y asumida coincidencia entre Bajtín y la Sociocrítica. Dominada como está la escuela montpelleriana por el paradigma semiótico, al cual Bajtín le dedica unas cuantas parrafadas no muy amistosas, al referirse sobre todo al 
concepto de unidad y coherencia, es posible que tales coincidencias lo sean tan sólo en las hipótesis secundarias de las respectivas teorías. Esto está por discutirse.

Una inquietud muy generalizada se cierne sobre este congreso de 1999, especialmente en los círculos sociocríticos de Hispanoamérica. Se trata del retiro de E. Cros. Aunque se dice que seguirá a cargo del IIS, su jubilación podría implicar un deterioro en la fortaleza institucional de la disciplina y en los lazos académicos de la Universidad de Montpellier con el resto de los centros afiliados. Porque, siendo honestos y francos, una figura como la de Cros, que goce del reconocimiento y prestigio internacional que él tiene, es difícil de sustituir.

Una empresa como esta que acabamos de describir abordando tanto su minimum epistemológico como su devenir histórico, y que ha servido tan bien al desarrollo intelectual de tantos académicos jóvenes y a la difusión de la cultura y las literaturas hispánicas, sería una verdadera lástima que se desmantelara, aunque no dudamos de la disposición de alguno de los centros afiliados para continuarla.

\section{La experiencia sociocrítica en las aulas de la Universidad de Costa Rica (Balance personal de una docente)}

Este apartado es parte de la ponencia llevada por la autora de este artículo al IIdo. Congreso Internacional de Sociocrítica. Guadalajara, México. 1993.

Si consideramos la ciencia como una empresa histórica, podríamos señalar que la evolución del pensamiento científico describe una trayectoria que va del pensamiento puramente especulativo (pre-científico en sentido estricto), al positivismo en sus diferentes versiones, hasta la reacción que destaca el carácter relativo y progresivo del conocimiento. Esta última concepción, que es impulsada por los filósofos de la ciencia del presente siglo, es una concepción más rica y compleja del quehacer científico, pues pondera el peso de los factores subjetivos y está más conciente de la dialéctica entre los supuestos epistemológicos y los datos empíricos en el proceso de conocimiento.

Hay en ella, entonces, una negación tácita de la transparencia de la realidad y la percepción no es vista como una resultante pura y simple de los estímulos o sensaciones; razón por la cual lo que percibimos está cargado de subjetividad, o de significación, de acuerdo con valores culturalmente condicionados. Por lo tanto, a la par de la percepción entra en juego la interpretación. Pero entre la percepción y la interpretación hay un salto cualitativo y la teoría vendría a ser el vínculo que posibilita ese salto.

Si dentro de ese marco en que, según Khum, se albergan las aspiraciones de la comunidad científica contemporánea, ubicamos a la Sociocrítica, ella no solo debería responder muy adecuadamente a esos valores, sino que, además, como experiencia del lenguaje y de la hermenéutica (Gadamer) estaría llamada a jugar allí un papel importante, al menos como planteamiento teórico, porque, en la práctica, en la experiencia, encuentra serias dificultades para favorecer el salto cualitativo del que hablábamos.

En la enseñanza de esta disciplina a lo largo de casi dos décadas, he sufrido solitariamente la sensación de que la demanda cognoscitiva implícita en la Sociocítica supera en la 
mayor parte de los casos las posibilidades de mis esudiantes. Lo que me consuela es que esta debilidad se ha mostrado también en algunos trabajos que los mismos docentes han llevado a los congresos internacionales de Sociocrítica. Estos trabajos parecen agotarse en lo descriptivo, es decir, en la observación, selección, recopilación, clasificación y sistematización de ciertos fenómenos textuales para cuya captación sensibiliza la Sociocrítica, pero sin haber logrado finalmente el salto cualitativo, el momento valorativo, como diría Bajtín.

Un rápido examen del campo nocional de la Sociocrítia evidenciaría el empleo de conceptos provenientes de diferentes regiones del saber, pues se trata de una ciencia transdisciplinaria. Es necesario, pues, conocer el valor de origen de estas nociones, tener conciencia de la posición que ocupan en su propio sistema y luego observar la nueva valencia que adquieren en nuestra disciplina. Si no se entienden esos conceptos, que no tienen un mero uso metafórico, y el valor que adquieren en el sistema explicativo que propone la Sociocrítica, se pierde de vista su núcleo epistémico y metafísico. Creo que esa es una de las razones que obstaculizan el salto cualitativo.

Para aprender sociocrítica es necesario, entonces, aprehenderla sociocríticamente, haciendo arqueología del saber, como diría Foucault, y procediendo con ella de la misma manera que ella propone que se proceda con los textos.

A esta conclusión llegué al cabo de muchos tropiezos y frustraciones que me obligaron a reflexionar sobre el método de enseñar el método. De modo que la Sociocrítica debe enseñarse como un discurso, más que como un recurso. Por lo tanto, es necesario plantear su propio genotexto y los códigos de transformación con los que ese genotexto procesa la interdiscursividad y la intertextualidad de la disciplina misma.

No se trata, entonces, de repetir a Cros, a Gómez Moriana o a Duchet, sino de pensar en su pensar, en su estilo cognoscitivo. No importa tanto la definición de intertextualidad o de interdiscursividad, por ejemplo, sino que, más bien, se trata de reflexionar en el paradigma geométrico que Cros utiliza para explicarlas y en la importancia de insertar un tercer eje: el del autoengendramiento, pues en el momento en que ese eje se inserta estamos pasando de una geometría plana a una geometría del volumen y quizá hasta una topología textual; por algo la cinta de Möebius se usa como metáfora epistemológica de las mediaciones.

Tener conciencia de lo que es un volumen y el significado de la tercera dimensión que lo hace posible no es otra cosa que la invocación de una demanda cognoscitiva superior a la mera repetición de las nociones de intertexto e interdiscusividad. Por lo tanto, es hacia allí a donde deberían apuntar todas las baterías del proceso de enseñanza-aprendizaje y no hacia la captación mecánica de las nomenclaturas.

Esto obliga al docente a ser más creativo en sus estrategias didácticas. En ese esfuerzo, algunas veces logrado y otras no, puedo mencionar experiencias inverosímiles en el aula, como, por ejemplo, enseñar el concepto de género como hipercodificación con la ayuda de un camello, o ilustrar el papel de los pre-asertados con la fotografía de un chimpancé. Este recurrir a lo visual (Foucault lo hizo con Las Meninas para explicar el fenómeno de la representación) me ha dado excelentes resultados para mostrar la diferencia entre lo percibido y lo interpretado y recorrer de manera progresiva los distintos niveles de abstracción.

Sin embargo, eso no es todo. Como ya se ha dicho, la Sociocrítica reúne las mejores contribuciones teóricas de la modernidad, tanto de nuestro propio campo como de otros, lo que hace que la comprensión de esta disciplina se tenga que hacer en referencia constante a 
otras poblaciones conceptuales. Esto quiere decir que la información es apabullante y su procesamiento sumamente doloroso para el estudiante.

Esa es la razón por la que la Escuela de Filología ha colocado estos seminarios a la altura de la licenciatura, pues considera que esos cursos cumplen una función integradora de los contenidos de los diferentes programas de teoría como de literatura que el estudiante ha llevado en el plan de estudios del bachillerato universitario.

La tarea no es fácil, pero el reto es fascinante y ha sido bien recibido por los estudiantes, lo cual se demuestra en el hecho de que la Sociocrítica se ha mantenido como una oferta académica en la Escuela de Filología y en el Posgrado en Literaturas Hispánicas, desde 1984. En estos quince años, el Departamento de Lengua y Literatura lo ha ofrecido ininterrumpidamente y el posgrado de literatura de modo bastante frecuente también porque, siendo un curso optativo, su demanda por parte de los estudiantes todavía continúa.

\section{Bibliografía}

Albán, Laureano. 1984. “Biografías del terror”. Imprévue. Poésies engagées. Montpellier. 1.

Amoretti Hurtado, María. 1987. Debajo del canto. (Análisis del Himno Nacional de Costa Rica). San José: Editorial de la Universidad de Costa Rica.

1989. Introducción al sociotexto. (A propósito de Cachaza). San José: Editorial de la Universidad de Costa Rica.

1993. Diccionario de términos asociados en teoría literaria. San José: Editorial de la Universidad de Costa Rica.

"Sobre la corrupción del lenguaje". En Semanario Universidad. № 1337, del 14 al 20 de abril. San José, Costa Rica.

Borsò, Vittoria. 1996. "Literatura y discurso o la mirada desde afuera. Impulsos de una "hispanoamericanística" internacional para la reorganización del saber en las ciencias humanas". Klengel. Alemania.

Bubnova, Tatiana. 1996. "Bajtín en la encrucijada dialógica (Datos y comentarios para contribuir a la confusión general”. En Bajtín y sus apócrifos. Barcelona: Anthropos. Coedición con la Editorial de la Universidad de Puerto Rico: 13-72.

Carcaud-Macaire, Monique. 1995. Pour une lecture sociocritique de l'adaptation cinématographique. Montpellier: CERS.

Carcaud-Macarie, Monique (ed.). 1997. Questionnement des formes. Questionnements du sens. Montpellier: CERS. Tomo I y tomo II. 
Chen Sham, Jorge. 1999. Fray Gerundio de Campazas o la corrupción del lenguaje. San José: Editorial de la Universidad de Costa Rica.

Cornea, Paul. 1976. "Tendences e orientations actuelles dans la sociologie de la littérature”. En: Synthesis. Bucarest, II.

Cros, Edmond. 1975. L'aristocrate et le camaval des gueux. Montpellier: CERS.

1976. Propositions pour une Sociocritique. Montpellier: CERS.

1980. Ideología y Genética textual. El caso del Buscón. Madrid: Planeta.

1983. Théorie et pratique sociocritiques. Montpellier: CERS.

1991. De l'engendrement des formes. Montpellier: CERS.

1995. D'un sujet a l'autre. Sociocritique et Psychanalyse. Montpellier: CERS.

Díaz-Diocaretz, Miriam e Iris Zavala. 1993. Breve historia feminista de la literatura española en lengua castellana. Madrid: Anthropos.

Duchet, Claude. 1979. Sociocritique. París: Nathasn.

Malcuzynski, Pierrette. 1991. Sociocríticas. Prácticas textuales / Cultura de fronteras. Amsterdam-Atlanta (Ga.): Éditions Rodolpi B.V.

Mora, Sonia Marta. 1995. De la sujeción colonial a la patria criolla. El Periquillo Sarniento y los orígenes de la novela en Hispano América. San José-Montpellier: Euna-CERS.

Ramírez Caro, Jorge. 1997. Los rituales del poder. San José: EUNA.

Trottier, Danièle. 1994. Juego textual y profanación. San José: Editorial de la Universidad de Costa Rica.

Zavala, Iris. 1991. Bajtín y la posmodernidad. Madrid: Espasa-Calpe. 